
8 Research Square
Preprints are preliminary reports that have not undergone peer review.
They should not be considered conclusive, used to inform clinical practice,
or referenced by the media as validated information.

\title{
Socioeconomic, intrapersonal and food environmental correlates of unhealthy snack consumption in Indian adolescents
}

\author{
Panchali Moitra ( $\triangle$ panchali2511@yahoo.co.in ) \\ Sir Vithaldas Thackersey College of Home Science (Autonomous), SNDT Women's University \\ Jagmeet Madan \\ Sir Vithaldas Thackersey College of Home Science (Autonomous), SNDT Women's University
}

\section{Research Article}

Keywords: adolescent snacking, unhealthy snack consumption, food environment, snacking habits of adolescents, Indian adolescents, socioeconomic status, factors of snack consumption, snacking behaviors of adolescents in India

Posted Date: February 14th, 2022

DOI: https://doi.org/10.21203/rs.3.rs-1327783/v1

License: @) (1) This work is licensed under a Creative Commons Attribution 4.0 International License. Read Full License 


\section{Abstract}

Background: Unhealthy snacking habits in adolescents are typically triggered by obesogenic food environments and possibly perpetuated through interactions between socio-environmental factors and personal perceptions, attitudes, and motivations to change eating behaviors. This study attempted to address the knowledge gap regarding the association of intrapersonal, socioeconomic, and food environmental characteristics with unhealthy snack consumption in Indian adolescents, presenting several culturally situated targets for effective interventions.

Methods: A representative sample of 10-12 years old adolescents (n 712) completed a cross-sectional survey including eating habits, characteristics of school and home food environments, and perceptions related to affordability, convenience, and barriers within the food environments. The frequency of unhealthy snack consumption was assessed using a validated qualitative food frequency questionnaire. Multivariate regression analyses determined the associated factors of unhealthy snack consumption in adolescents attending private and public schools.

Results: The mean age of adolescents was 10.9 (1.1) years, $48.2 \%$ were girls and $53.9 \%$ attended private schools. The most frequently consumed unhealthy snacks were biscuits/ cookies $(5.2 \mathrm{~d} / \mathrm{wk})$ followed by wafers $(3.4 \mathrm{~d} / \mathrm{wk})$ and Indian fried snacks- samosa/ vada pav ( $2.8 \mathrm{~d} / \mathrm{wk})$. Among the public-school adolescents, the odds of unhealthy snack consumption were 0.89 times lower when meals were had frequently at the dinner table and 4.97 times higher when the perceived barriers related to the affordability of healthy snacks were greater. Maternal education (OR $0.78,95 \% \mathrm{Cl} 0.66-0.82,<0.001$ ), family income (OR 2.15, 95\% Cl 1.98-2.32, p < 0.001), availability of unhealthy snacks (OR 2.98, 95\% $\mathrm{Cl} 1.36-3.46, \mathrm{p}<0.001)$ and fruits at home (OR 0.57, 95\% $\mathrm{Cl} 0.49-0.69, \mathrm{p}<0.001)$, having evening meals together (OR $0.71,95 \% \mathrm{Cl} 0.63-0.81, \mathrm{p}$ 0.031 ), and perceived parental control during mealtimes (OR $0.67,95 \% \mathrm{Cl} 0.62-0.72, \mathrm{p}<0.001$ ) were associated with unhealthy snack consumption in adolescents attending private schools.

Conclusions: The results highlighted a pervasiveness of unhealthy snacks in adolescents' food environments. Improving provisions and affordability of fruits and healthy snacks at schools, encouraging family mealtimes, limiting the availability of unhealthy snacks at home whilst addressing the perceived barriers within food environments, and inculcating selfefficacy skills can improve snacking habits in Indian adolescents, irrespective of socioeconomic backgrounds.

\section{Introduction}

Early adolescence is a nutritionally vulnerable period of life that is marked by an increase in personal autonomy over food choices and a greater influence of the socio-environmental factors on eating behaviors as compared to childhood (1-3). Evidence suggests that unhealthy eating habits such as increased consumption of energy-dense and nutrient-poor snacks at the expense of healthier fruits and vegetables are often established and reinforced during adolescence (4-6). Moreover, studies have reported a ubiquitous snacking habit among adolescents (7-9) and that the foods and beverages consumed as snacks may contribute to $\sim 20-25 \%$ of their daily energy intake $(10,11)$. Given the well-documented understanding that poor snacking habits are typically triggered by obesogenic food environments in adolescents' immediate settings such as schools and homes (12-14) and an expedient need to identify culturally situated targets for interventions that promote healthy dietary practices during adolescence and prevent the risk of obesity and other chronic diseases later in adulthood, the determinants of unhealthy snacking behaviors in adolescents must be delineated. This attains particular importance for adolescents residing in the urban cities of rapidly globalizing economies such as India where shifts in the availability, affordability, and desirability of foods consumed are driving an unfavorable nutrition transition (15-17) and a concomitant burden of obesity amidst the persisting challenges of undernutrition continues to pose significant public health challenges (18-20).

Previous studies have identified food environmental exposures such as the sale of unhealthy foods at schools, availability, and accessibility of healthy foods at home, and familial influences such as parents' nutrition knowledge and family dietary practices as correlates of food consumption in adolescents (21-23). However, the majority of the relevant evidence 
originates from developed countries and little is known about the socio-cultural, economic, and food environmental characteristics of adolescents in India and how they come together to influence snacking habits. Furthermore, the depth and pace of the influences of food environments on snacking behaviors are likely to vary between the urban rich and urban poor due to probable inequities in access and affordability of foods (24-26). While several studies have established a distinct socio-economic gradient in the food consumption patterns and have reported associations between socioeconomic disadvantages and poor diet quality in adults(27), the research regarding the influence of socio-economic status (SES) of families on adolescents' snacking habits is limited and the socio-economic differentials in the school and home food environments of adolescents in India have not yet been investigated.

Besides the food environmental factors of consumption patterns, there is evidence that adolescents' attitudes and perceptions towards healthy eating can influence their snacking habits (28-31). For instance, a recent study among 12-17 years old adolescents observed positive associations between adolescents' autonomous motivation and dietary habits (32), and a cross-sectional study reported perceived barriers and self-efficacy as key determinants of adolescents' eating behaviors (33). To date, few studies have examined the school and home food environments of Indian adolescents and there are fewer studies that have explored the perceptions towards eating behaviors and food environments in adolescents in India. The few studies that were conducted were either among older adolescents (14-16 years old) attending private schools (34) or had employed qualitative study designs (35-37).

This study attempted to address the gaps in the knowledge regarding socioeconomic and food environmental exposures as correlates of unhealthy snack choices in adolescents and the critical role that the interplay of these environmental factors with adolescents' perceived barriers within food environments, self-efficacy, and readiness to change unhealthy habits may play in moderating their snack consumption patterns. Consistent with the ecological model of health promotion, improving snacking habits of adolescents will require a comprehensive investigation of the relationship between various intrapersonal, socioeconomic, and environmental factors. Therefore, the present study was conducted to evaluate the association of demographic, socioeconomic, food environments, and perception related factors with the consumption patterns of unhealthy snacks that are high in fat, salt, and sugar among 10-12 years old adolescents in Mumbai, India.

\section{Methods}

\section{Study design and setting}

This cross-sectional study was conducted in six coeducational schools (three unaided private and three government-aided public schools) in Mumbai, India. For administrative purposes, the district administration of the Greater Mumbai area is divided into seven zones and each of these zones comprises 3 to 5 administrative wards (38). For the study, two wards from a randomly selected zone were selected and twenty private and twenty public schools from the selected wards were invited to participate. The first three private and public schools each that provided permission were selected as the study sites.

\section{Participants}

All students, attending grades 6 and 7 at the selected schools $(n=6)$ were eligible to participate. Out of 1086 eligible students, 765 (70.4\% of those invited to participate) provided written parental consent and 712 adolescents completed the survey. Given that in India, private schools are typically attended by students who belong to upper or upper-middle-class families and public schools cater to low-middle and low socioeconomic backgrounds. Similar to previous studies, the type of school attended by adolescents was used as a proxy indicator of the SES $(15,39)$. The study protocol was approved by Intersystem Biomedica Ethics Committee, Mumbai, India (Approval Version 02/ dated 19 February 2019). Written informed consent from parents and written informed assent were obtained from adolescents. 


\section{Sample size estimation}

The sample size was estimated to be 323 at 5\% precision, $95 \%$ Confidence Interval $(\mathrm{Cl})$ with the assumption that $70 \%$ of urban adolescents in India practice unhealthy eating behaviors $(8,40,41)$. After taking into account a $20 \%$ non-response rate and a proportional representation from adolescents attending private and public schools, the sample size was calculated as 775 .

\section{Measures}

\section{Socio-demographic characteristics}

Adolescents reported their age, sex, grade (grade 6 or 7), type of living arrangement (nuclear or joint), and religion (Hindu, Muslim, Christian, and others) and the parents/caregivers provided socio-economic information- parents' highest educational qualifications and the family's monthly income (Table S1).

\section{Eating habits}

Adolescents provided information about eating habits such as weekly frequencies of consuming breakfast at home, carrying lunch or snacks to school, and watching television while eating at home. Adolescents were asked 'In the last 7 days, how many days did you perform the following activities....". The response options, 'never' to 'always, indicating < 1/week to 6-7 times/ week, were scored on a five-point scale from 0 to 4 . Higher scores indicated a higher frequency of indulging in a specific eating habit.

\section{Consumption of unhealthy snacks}

In line with the previous studies $(7,10,42)$, the snacks that are high in calories, salt, and sugar content and low in nutrients were considered unhealthy. We employed a brief qualitative food frequency questionnaire (FFQ) to assess adolescents' consumption of unhealthy snacks during the past week. The FFQ was validated as a part of our previous study to evaluate the practices related to healthy eating in 10-12 years old adolescents in Mumbai (43). In summary, the steps involved creating a list of locally available and commonly consumed unhealthy snack items based on the review of previous studies and the results of a pilot study entailing two non-consecutive interviewer-administered 24-hour diet recalls (24h DR) in adolescents $(n=55)$ in Mumbai. This was followed by the development of a food list comprising 28 snacks that were high in fats, sugar, and salt. This FFQ draft was next pretested among adolescents $(n=32)$ who were asked to report the weekly frequencies of consuming specific foods and indicate the most appropriate portion sizes of the consumed food items in standardized household measures such as katoris (bowl or cup), spoons, and glasses. Food items that were consumed infrequently (less than once a week) and/or had lower mean daily intakes $(<10 \mathrm{~g} / \mathrm{d})$ were removed from the list. For data sorting and analysis, similar items were grouped into four broad categories- (1) Snacks high in fat/ fast foods - 4 items (2) Snacks with added sugar - 3 items (3) Snacks with added salt - 4 items and (4) carbonated beverages - 1 item. The FFQ responses were scored 0 to 4, from 'never' to '2- 3 times a day. The scores corresponding to the consumption of all snack items were aggregated to derive total unhealthy snack consumption scores, possible scores 0 to 48 , with higher scores reflecting higher consumption of unhealthy snacks. The aggregate unhealthy snack consumption scores were subsequently categorized into tertiles indicating high, moderate, and low consumption. Moreover, the consumption frequencies were calculated as the number of days/ weeks by coding the response options 'never' as $0 \mathrm{~d} /$ week, 'sometimes' as $1.5 \mathrm{~d}$ /week, 'often' as $3.5 \mathrm{~d} /$ week, 'frequently' as $5.5 \mathrm{~d} /$ week, and 'always' as $7 \mathrm{~d} /$ week. 


\section{School and home food environments of adolescents}

The school and home food environment-related questions were based on a 36 item self-reported questionnaire measuring Food-Related Environments at Schools and Homes (FRESH-Q) in adolescents in India (44). The specific items in the questionnaire were developed based on the results of focus group discussions with adolescents, parents, and teachers reported elsewhere (31) and a thorough review of other food environment-related questionnaires administered in adolescents (45-48). In the questionnaire, the school food environment items examined the type, price, and quality of foods and beverages available for sale in the school canteens or at the nearby street vendors for the schools that did not have an on-site canteen. The adolescents were asked 'Do you eat at the school canteen or buy foods/beverages at school?' and 'If yes, then how often...? Additional questions included 'Which of the following foods and drinks are available at school to buy?', 'Which of the following foods and drinks do you usually buy at school?', and 'Why do you buy these foods? (Response options included taste, price, availability, and convenience)'.

To explore factors within home food environments, the adolescents were asked to report the weekly frequencies of availability and accessibility of unhealthy snacks at home. The participants were asked 'In the last 7 days, how many times were the following foods available at home' and 'how many times were the following foods kept in easy to reach places such as countertops or kitchen cabinets? The listed food items included the same 11 unhealthy snack items and 1 carbonated beverage item as reported in FFQ. Moreover, three questions assessed the perceived parental control during mealtime. Response options were 'strongly disagree' to 'strongly agree', scored from 0 to 4, with higher scores indicating higher perceived parental control on adolescents' consumption patterns. An additional three questions examined the family dietary habits such as weekly frequency of eating out or ordering takeaways, having at least one meal/d with family, and having meals at the dinner table.

The content validity of the questionnaire was examined by a panel of four experts including two public health nutritionists, a food environment researcher, and an academician. The principal axis method of exploratory factor analysis was used to establish the construct validity and the internal consistency was evaluated using Cronbach alpha values $>0.7$ (44). To test the reliability of the items in FRESH-Q, a sample of adolescents $(n=108)$ took a retest of the same questionnaire after two weeks and the test-retest correlation coefficient values of each item were calculated. Based on the content and construct validity measures and the internal consistency and test-retest correlation values, the items were retained or excluded in the final instrument. The summary of items included in the questionnaire is provided in Supplementary Material, Table S1.

\section{Perceptions of barriers in food environments}

The adolescents' perceptions related to eating behaviors and food environments were measured using sixteen statements, based on the constructs of a widely used health behavior framework, the Health Belief Model (HBM). The items assessed adolescents' perceived susceptibility and severity of adverse consequences of unhealthy eating behaviors, perceived barriers and benefits within food environments, and readiness to change and self-efficacy to adopt healthier dietary practices (49). Responses to the statements were assessed on a five-point Likert scale from 'strongly disagree to strongly agree', numeric scores 0 to 4 .

\section{Pilot testing of the questionnaire}

The face validity of the questionnaire including socio-demographic characteristics, eating habits, frequency of consumption of unhealthy snacks, food environments, and adolescents' perceptions were evaluated in 34 adolescents, ages 10-12 years (20 from a public school and 14 from a private school). These participants were not included in the final data analysis. All the questions were well understood, and no revisions were considered. The field investigators having postgraduate degrees in nutrition received a full day of training to review the protocol and methods of data collection. The 
questionnaire was administered to adolescents during school hours in the presence of school teachers and the trained field research team. The summary of items in the questionnaire is provided in Supplementary Material Table S1.

\section{Statistical Analysis}

Adolescents $(n=712$; private schools $n=384$ and public schools $n=328)$ who were present in school on the survey day and had provided $>70 \%$ of complete information and a written, informed assent to participate in the study comprised the final sample for analysis. The data were analyzed using IBM SPSS for Windows version 20.0 (IBM Corporation, Armonk, NY, USA). Assuming a normal distribution, the demographic variables, eating habits, unhealthy snack consumption patterns, food environments, and perceptions were compared between private and public-school adolescents using frequency analysis, chi-square statistics, cross-tabulation, and student t-tests. For the comparative analysis of perceptions between private and public-school adolescents, the response options of 'strongly agree' and 'agree' were categorized as a single category and 'strongly disagree' and 'disagree' as another while the response option 'neither agree nor disagree' was retained as a separate category. Univariate regression analyses were performed to determine the unadjusted effects of independent variables - demographic and food environment characteristics, eating habits, and adolescents' perceptions on the dichotomized dependent variables- unhealthy snack consumption (highest tertile of aggregate scores indicating high consumption of unhealthy snacks and moderate/lowest tertiles of consumption) in separate models for private and publicschool adolescents. Next, we used a backward stepwise logistic regression method to eliminate the least significant predictor variables and derive a reduced model that best explained the data. The independent variables that remained were entered as the covariates in the final multivariate regression model and the adjusted odds ratio with $95 \%$ confidence interval $(\mathrm{Cl})$ of odds ratio were calculated, considering $\mathrm{p}$ values $\leq 0.05$ as a measure of significant association between variables.

\section{Results}

\section{Demographic variables}

Of the 712 adolescents who completed the survey, $48.2 \%$ were girls, $46.1 \%$ attended public schools and $50.8 \%$ were sixth graders (Table 1). The mean age of adolescents was 10.9 (1.1) years. Significant differences were observed in parents' education status and family's monthly income between adolescents attending private and public schools. (INSERT TABLE 1)

\section{Eating habits of adolescents}

Breakfast was 'never' consumed at home before leaving for school by $28.8 \%$ and tiffin (lunch box) was 'sometimes' carried to school by $65.4 \%$ of adolescents. Overall, $22.3 \%$ reported 'never' carrying fruits in their tiffins (lunch boxes), $41.2 \%$ 'often' or 'frequently' carried unhealthy snacks such as biscuits, chocolates, or wafers to school and $70.6 \%$ mentioned watching television or screen devices while eating meals at home at least 5-6 times/ week (response options, 'frequently' or 'always') (Table 2) (INSERT TABLE 2).

\section{School and home food environments}

Overall, $76.1 \%$ reported purchasing foods and/or beverages at schools at least $1-2$ times a week, $86.0 \%$ mentioned that unhealthy snacks were 'almost always' available for sale at canteens and $45.0 \%$ had purchased unhealthy snacks at school $>3$ times in the past week. The predominant factors determining the purchase of specific foods at school were reported as taste $(70.9 \%)$ followed by price (48.0\%) and availability of foods (32.2\%) at schools. Only $44.7 \%$ had evening 
meals together with their family 'every day', $23.5 \%$ would 'sometimes' have meals at the dinner table and $70.1 \%$ had eaten out at restaurants/ordered takeaways at least 1-2 times in the last week. While $44.8 \%$ reported healthy snacks to be 'never/ sometimes' kept in easy to reach places at homes, $73.9 \%$ mentioned that unhealthy snacks such as wafers, namkeen, biscuits, Kurkure were 'always/frequently' kept in easy to reach places (Table 2).

\section{Frequency of consumption of unhealthy snacks}

The weekly consumption frequencies of unhealthy snack items are presented in Table 3 . The most frequently consumed unhealthy snacks were biscuits/ cookies (5.2d/wk) followed by wafers/ potato chips (3.4d/wk) and Indian fried snackssamosa/ vada pav (2.8 d/wk). Private school participants reported a higher frequency of consumption of fast foods such as Pav bhaji and burgers/ pizzas, snacks with added salt (wafers/ potato chips and fried rice/ noodles), and carbonated beverages than those from public schools. The frequencies of consumption of relatively lower-priced snacks such as biscuits/ cookies and Chinese bhel (popular street food in Mumbai) were observed to be more among public school participants. No significant differences were observed in the frequency of consumption of samosa/ vada pav, instant noodles, and chocolates between public and private school adolescents (INSERT TABLE 3).

\section{Comparison of eating habits, unhealthy snack consumption, and food environments between public and private school adolescents}

As shown in Supplementary Table 2, a higher frequency of carrying snacks (tiffin), fruits, and healthy snacks to school was observed in private school adolescents as compared to those attending public schools. However, there were no significant differences in the weekly frequency of carrying unhealthy snacks to school or watching television/screens while eating. Private school adolescents reported a higher frequency of consuming snacks high in fat/ fast foods and carbonated beverages but not snacks with added sugar or salt. Regarding the characteristics of food environments at schools and home, differences were observed in the availability of healthy snacks at schools, availability of fruits and carbonated beverages at home, frequency of having evening meals together, and perceived parental control during mealtime scores in private and public-school adolescents (INSERT Supplementary Table 2)

\section{Comparison of perceptions related to eating behaviors and food environment between public and private school adolescents}

More than two thirds (67.1\%) mentioned that 'fruits are not available at school canteens', three fourths (76.1\%) reported that 'home-cooked foods are always same and boring' and the majority (87.8\%) agreed that the 'snacks brought from home become cold and unpleasant' (Table 4). A higher proportion of private school participants agreed to have enough knowledge to make healthy food choices (self-efficacy) and try to eat fruit every day (readiness to change) as compared to those from public schools $(p<0.05)$. (INSERT TABLE 4).

\section{Factors associated with unhealthy snacks consumption}

Among the adolescents attending public schools, the odds of unhealthy snack consumption were 1.75 times higher in boys, 2.60 times higher when unhealthy snacks were available $>3$ days/ week at schools, and 0.89 times lower when meals were had at the dinner table more frequently (Table 5). Also, higher consumption of unhealthy snacks was observed to be associated with greater perceived barriers in school and home food environments and lower readiness to change eating habit scores. For the private school attending adolescents, we observed that mothers' education $(\mathrm{OR} 0.78,95 \% \mathrm{Cl} 0.66-$ $0.82,<0.001)$, family income (OR $2.15,95 \% \mathrm{Cl} 1.98-2.32, \mathrm{p}<0.001)$, availability of unhealthy snacks $(\mathrm{OR} 2.98,95 \% \mathrm{Cl} 1.36-$ 
$3.46, \mathrm{p}<0.001)$ and fruits at home (OR $0.57,95 \% \mathrm{Cl} 0.49-0.69, \mathrm{p}<0.001)$, having evening meals together (OR $0.71,95 \% \mathrm{Cl}$ $0.63-0.81, \mathrm{p} 0.031$ ), and perceived parental control during mealtimes ( OR $0.67,95 \% \mathrm{Cl} 0.62-0.72, \mathrm{p}<0.001$ ) were associated with consumption of unhealthy snacks. (INSERT TABLE 5)

\section{Discussion}

This study is one of the few to concurrently explore the characteristics of school and home food environments of adolescents in India and the first to examine the socioeconomic, food environmental, familial, and intrapersonal factors of unhealthy snack consumption in Indian adolescents. The results highlighted that the correlates of unhealthy snack choices in adolescents are multifaceted and range from demographic characteristics to various social and food environmental factors within the adolescents' immediate settings at schools and homes. The key findings that emerged from this study were 1) a frequent consumption of unhealthy snacks high in fats, added sugar, and salt among adolescents, irrespective of the type of school attended (used as a proxy indicator for SES), 2) a pervasiveness of energy-dense and nutrient-poor snacks in the school and home food environments of adolescents, 3) low levels of perceived severity of adverse consequences of unhealthy snack consumption, readiness to change habits and perceived parental control during mealtimes, and 4) a significant association of maternal education level, family income, availability of unhealthy snacks at schools and homes, frequency of having family meals and adolescents' own perceived barriers within the food environments with their unhealthy snack consumption patterns.

In general, the adolescents attending private schools reported healthier eating habits (such as higher frequency of having breakfast at home before going to school, carrying fruits as snacks to school, and purchasing healthy snacks at school) and food environments (such as greater availability of fruits for sale at schools, better accessibility of fruits and healthy snacks at homes, and a higher perceived parental control during mealtime) than those attending public schools. These findings can be explained by a higher SES of private school families that might have resulted in better affordability of relatively higher-priced fruits and healthy snacks $(26,50)$ and a higher level of parents' education that could have contributed to greater awareness of the benefits of healthy eating and more supportive family food environments (25). Previous studies, conducted outside India have reported similar associations between low socioeconomic position, low availability of healthy foods at home, poor mealtime habits, and limited parental encouragement of healthy eating habits in adolescents (51-53).

In contrast to the majority of evidence from high-income countries that suggest higher consumption of cheap, energy-dense unhealthy foods among lower SES, we observed a somewhat blurring line in the SES-related differentials in adolescents' unhealthy snack consumption in the present study. While the private-school adolescents reported more frequent consumption of expensive unhealthy snacks such as restaurant bought burgers and pizzas or branded processed foods with added sugar and salt such as cakes and wafers, a higher frequency of consumption of the cheaper versions of similar nutritionally poor, high-calorie snacks such as biscuits, fried Indian snacks, and unhealthy street foods was observed in adolescents attending public schools. In the context of the ongoing nutrition transition and its impact on food preferences and health outcomes in adolescents, these findings draw concerns regarding frequent consumption of unhealthy snacks in urban adolescents in India, irrespective of their socioeconomic backgrounds. Given the well-documented associations between unhealthy food consumption and risk of nutrition-related lifestyle disorders $(54,55)$, age and culturally appropriate initiatives that build awareness and foster positive attitudes are increasingly warranted to limit unhealthy snacking habits in Indian adolescents across SES.

Adolescents spend a substantial amount of time at schools, so health-promoting SFE can act as enablers of reduced unhealthy snack consumption. In our study, the majority of participants reported purchasing foods and/ beverages at 
school canteens. The most frequently bought foods at school canteens, irrespective of the type of school attended, were unhealthy snacks such as wafers, chocolates, and fried Indian snacks- samosa and vada pav. While fruits and healthy snacks were reported to be available in the private school canteens, these items were rarely bought as snacks. This suggests that the availability of fruits and healthy snacks are necessary to allow access to healthy food options but may not necessarily result in better intake unless the availability of unhealthy foods for sale in schools is restricted. Similar insights were reported in previous studies (37,56-59). Thus, suitable measures must be taken to simultaneously reduce access to unhealthy foods and improve the provision of healthy food and beverage alternatives to 'tasty' and 'cheap' unhealthy snacks at schools in India. Introducing behavior change interventions to improve acceptability and sustainability of modifications within school food environments and employing stringent school food policies regarding accessibility to nutrient-poor and energy-dense snacks at school canteens may add further leverage.

Besides the influences of school food environments, analyses showed associations of familial factors such as frequency of eating out, having dinner at the table, and having evening meals together and home food environment characteristics such as availability and accessibility of unhealthy snacks at home with the consumption patterns. Better availability of fruits at home, having meals at the dinner table and greater parental control during meals were observed to be associated with lower unhealthy snack consumption. These results are consistent with previous studies $(22,60-63)$, and reiterate the significance of modifying the key dimensions of food environments at homes such as encouraging family mealtimes and increasing the availability of fruits and healthy snacks at home to improve eating behaviors in adolescents. Although this study did not assess parental intakes or perceptions, our findings indicated that parents' encouragement to adolescents to include vegetables at meals, setting family rules, and improving home availability of healthy foods can result in a lower frequency of consumption of unhealthy snacks. This brings forth the critical roles that parents play in the pursuit of improving the overall diet quality of adolescents. Targeted strategies that build nutritional knowledge and instill positive attitudes towards the benefits of healthy eating among parents along with a supportive home food environment are likely to encourage healthier food choices in adolescents.

Another significant observation was that the influence of perceptions of the barriers and facilitators within the food environments on adolescents' snack consumption frequencies. In this study, negative perceptions (limited availability of fruits at school, relatively high cost of healthy snacks, and lack of variety in home-cooked foods) and positive attitudes (readiness to change and self-efficacy when adopting healthy habits) were associated with adolescents' snacking patterns. These findings corroborate the evidence from previous qualitative investigations $(31,34)$ and quantitative studies grounded in health behavior theories $(5,31,48,64)$. Integrating food environment interventions with policy approaches that address perceived barriers and endorse social support through active peer and family engagement may facilitate and maintain reduced unhealthy snack consumption. Furthermore, differences were observed in the perceptions of private and publicschool adolescents, particularly for the perceived barriers of food environments. This implies that socio-economic disparities in the perceptions and the related opportunities and challenges to intervening within the food environments must also be considered in future advocacy efforts promoting healthier eating behaviors in adolescents.

There are a few limitations of this study. First, adolescents, ages 10-12 years were selected for the study. This sample selection method limits the generalizability of the results to younger or older adolescents in India. Yet, the period of early adolescence is considered an important phase of life when individuals start to develop an understanding of how their present eating habits may influence future wellbeing. Understanding the correlates of snacking behaviors at this age is likely to pave for early intervention strategies with long-lasting health benefits. Second, the measures were self-reported, so they can be subject to recall or reporting bias. However, to minimize the bias, we evaluated the psychometric properties of the questionnaire used to capture food environmental factors before administration in adolescents and used a validated food frequency questionnaire to estimate unhealthy snack consumption. Future research may consider the employment of direct observations of the availability, price, and quality of foods sold in schools and of factors within a home food environment such as the availability and visibility of foods by trained raters to reduce any potential bias in self-reported observations. Third, given the complex and multifactorial impact of social and food environments on eating behaviors, 
some factors could have been missed, though attempts were made to include most of the common and relevant determinants, as indicated in previous studies.

The novelty of this study lies in the evaluation of different individual and environmental factors in a single study and an investigation into the influences of these exposures on unhealthy snack consumption in adolescents. Several foodenvironmental and individual-level factors were identified as correlates of unhealthy snack consumption in adolescents, presenting targets for future intervention programs. Given that the access and affordability of foods can influence the snacking behaviors of adolescents and that the SES differentials in food environments of adolescents in India are poorly understood, we compared the determinants of unhealthy snack consumption between adolescents attending private and public schools. The results suggested that sociodemographic characteristics such as gender, maternal education, and SES can be used to customize interventions and that a focus on the role of parents in shaping adolescents' diet quality must be emphasized. Other strengths of this study were that the personal factors that guide the food purchase decisions at schools were evaluated and the interplay between individual perceptions such as perceived barriers of food environments at schools and homes, perceived readiness to change and self-efficacy and adolescents' unhealthy snack consumption were explored. Also, the results provided valuable insights into the associations between adolescents' eating habits, parental control during mealtimes, and adolescents' unhealthy snack consumption. The findings of this study attempt to draw attention to the frequent availability of low-cost unhealthy snacks at schools, and limited availability of healthy snack options at home, and a need to integrate positive perceptions of healthy eating habits and self-efficacy skills into adolescent health and nutrition policies.

\section{Conclusions}

This study presented a comprehensive assessment of school and home food environments, and perceptions of eating behaviors in adolescents and how they come together to moderate adolescents' unhealthy snack consumption. The paucity of food environment research in India underpins the need to conduct a situational analysis of the local, neighborhood, school, and home food environments of adolescents. Additional research is also required to determine the socio-cultural, environmental, and contextual correlates of food choices in a larger and diverse sample. The findings posit that exploring the determinants of food choices within the immediate food environments of adolescents and designing feasible interventions targeted at optimizing these exposures present critical avenues to limit unhealthy snacking behaviors in adolescents. Since food environmental factors consistently interact with personal perceptions, attitudes, and motivations to engage in healthy eating behaviors, addressing the interplay of these factors may confer greater benefits on present and future health outcomes in adolescents.

\section{Declarations}

\section{Ethics approval and consent to participate-}

This study was conducted according to the guidelines laid down in the Declaration of Helsinki and all procedures involving research study participants were approved by Intersystem Biomedica Ethics Committee, Mumbai, India (Approval Version 02/ dated 19 February 2019). Written informed consent from parents and written informed assent were obtained from all participants involved in the study.

\section{Consent for publication-}

Not applicable

\section{Availability of data and materials-}


All data generated and /or analyzed during the current study are included in the published article and its supplementary information files.

\section{Competing interests-}

The authors declare that they have no competing interests

\section{Funding-}

This research received no specific grant from any funding agency, commercial or not-for-profit sectors.

\section{Authors' contributions-}

Conceptualization, methodology, software, investigation, and writing of the original draft of the manuscript were performed by PM. The fieldwork, data management, and analysis were supervised by JM and the final draft was critically reviewed by both authors before submission. The authors have read the final version of the manuscript and agree with the order of the presentation of the authors in the manuscript.

\section{Acknowledgments-}

The authors acknowledge the cooperation of principals and teachers of the participating schools and the valuable inputs provided by the study participants. Our appreciation is also due to the field staff and research assistants who worked diligently to maintain the quality of data collected and recorded. We would like to thank Mr. JC Sharma and Ms. Apurva Agashe for their assistance in the statistical analysis of the data.

\section{References}

1. Lassi Z, Moin A, Bhutta Z. Nutrition in Middle Childhood and Adolescence. Dis Control Priorities, Third Ed (Volume 8) Child Adolesc Heal Dev [Internet]. 2017 Nov 20 [cited 2021 Jul 9];133-46. Available from: https://www.ncbi.nlm.nih.gov/books/NBK525242/

2. Sivagurunathan C, Umadevi R, Rama R, Gopalakrishnan S. Adolescent health: Present status and its related programmes in India. Are we in the right direction? Journal of Clinical and Diagnostic Research. 2015.

3. World Health Organization. SEA-NUT-163 Distribution: General Adolescent Nutrition: A Review of the Situation in Selected South-East Asian Countries ii Adolescent Nutrition: A Review of the Situation in Selected South-East Asian Countries. 2006.

4. Pearson N, Griffiths P, Biddle SJH, Johnston JP, Haycraft E. Individual, behavioural and home environmental factors associated with eating behaviours in young adolescents. Appetite [Internet]. 2017 [cited 2018 Mar 30];112:35-43. Available from: http://www.ncbi.nlm.nih.gov/pubmed/28062200

5. Gebremariam MK, Henjum S, Terragni L, Elin Torheim L. Correlates of fruit, vegetable, soft drink, and snack intake among adolescents: The ESSENS study. Food Nutr Res [Internet]. 2016 Sep 20 [cited 2020 Nov 16];60. Available from: /pmc/articles/PMC5031794/?report=abstract

6. Popkin BM, Adair LS, Ng SW. Global nutrition transition and the pandemic of obesity in developing countries. Nutr Rev. 2012 Jan;70(1):3-21.

7. Feyzabadi VY, Mohammadi NK, Omidvar N, Karimi-Shahanjarini A, Nedjat S, Rashidian A. Factors Associated With Unhealthy Snacks Consumption Among Adolescents in Iran's Schools. Int J Heal Policy Manag [Internet]. 2017 Sep 1 
[cited 2022 Feb 2];6(9):519. Available from: /pmc/articles/PMC5582438/

8. Rathi N, Riddell L, Worsley A. Urban Indian adolescents practise unhealthy dietary behaviours. Br Food J. 2018;

9. Savige G, MacFarlane A, Ball K, Worsley A, Crawford D. Snacking behaviours of adolescents and their association with skipping meals. Int J Behav Nutr Phys Act. 2007 Sep 17;4.

10. De Vet E, Stok FM, De Wit JBF, De Ridder DTD. The habitual nature of unhealthy snacking: How powerful are habits in adolescence? Appetite. 2015 Dec 1;95:182-7.

11. Larson N, Story M. A review of snacking patterns among children and adolescents: what are the implications of snacking for weight status? Child Obes [Internet]. 2013 Apr 1 [cited 2022 Feb 2];9(2):104-15. Available from: https://pubmed.ncbi.nlm.nih.gov/23470091/

12. Scaglioni S, De Cosmi V, Ciappolino V, Parazzini F, Brambilla P, Agostoni C. Factors influencing children's eating behaviours. Vol. 10, Nutrients. MDPI AG; 2018.

13. Welker E, Lott M, Story M. The School Food Environment and Obesity Prevention: Progress Over the Last Decade [Internet]. Vol. 5, Current obesity reports. Curr Obes Rep; 2016 [cited 2020 Aug 30]. p. 145-55. Available from: https://pubmed.ncbi.nlm.nih.gov/27066793/

14. Schrempft S, Van Jaarsveld CHM, Fisher A, Wardle J. The obesogenic quality of the home environment: Associations with diet, physical activity, TV viewing, and BMI in preschool children. PLoS One. 2015 Aug 6;10(8).

15. Shaikh NI, Patil SS, Halli S, Ramakrishnan U, Cunningham SA. Going global: Indian adolescents' eating patterns. Public Health Nutr. 2016 Oct 1;19(15):2799-807.

16. Food and Agriculture Organization. Globalization of Food Systems in Developing Countries: Impact on Food ... - Food and Agriculture Organization of the United Nations - Google Books [Internet]. [cited 2020 May 17]. Available from: https://books.google.co.in/books?

$\mathrm{hl}=$ en\&lr=\&id=ggBcejopzy $Y C \& o i=f n d \& p g=P A 1 \& d q=$ globalization+india+food+environment\&ots=mK87AAhFEC\&sig=lKjx0AFdHGHhW00Fp13TDFsyBE\#v=onepage \&q=globalization india food environment $\&=$ false

17. Griffiths PL, Bentley ME. The Nutrition Transition Is Underway in India. J Nutr. 2018;131:2692-700.

18. Meharda B, Sharma SK, Singhal G, Kumar L. D. Overweight and obesity: a rising problem in India. Int J Community Med Public Heal. 2017;

19. Puwar T, Saxena D, Yasobant S, Savaliya S. Noncommunicable diseases among school-going adolescents: A case study on prevalence of risk factors from Sabarkantha District of Gujarat, India. Indian J Community Med [Internet]. 2018 [cited 2020 Aug 29];43(5):S33-7. Available from: /pmc/articles/PMC6324039/?report=abstract

20. Gupta DK, Shah P, Misra A, Bharadwaj S, Gulati S, Gupta N, et al. Secular trends in prevalence of overweight and obesity from 2006 to 2009 in Urban Asian Indian adolescents aged 14-17 years. PLoS One. 2011;

21. Ssewanyana D, Abubakar A, van Baar A, Mwangala PN, Newton CR. Perspectives on Underlying Factors for Unhealthy Diet and Sedentary Lifestyle of Adolescents at a Kenyan Coastal Setting. Front Public Heal. 2018 Feb 9;6.

22. Draxten M, Fulkerson JA, Friend S, Flattum CF, Schow R. Parental role modeling of fruits and vegetables at meals and snacks is associated with children's adequate consumption. Appetite [Internet]. 2014 Jul 1 [cited 2021 Apr 1];78:1-7. Available from: https://pubmed.ncbi.nlm.nih.gov/24630934/

23. Couch SC, Glanz K, Zhou C, Sallis JF, Saelens BE. Home food environment in relation to children's dietquality and weight status. J Acad Nutr Diet. 2014 Oct 1;114(10):1569-1579.e1.

24. Gill M, Feliciano D, Macdiarmid J, Smith P. The environmental impact of nutrition transition in three case study countries. Food Secur. 2015 Jun 1;7(3):493-504.

25. Agrawal S, Kim R, Gausman J, Sharma S, Sankar R, Joe W, et al. Socio-economic patterning of food consumption and dietary diversity among Indian children: evidence from NFHS-4. Eur J Clin Nutr. 2019;

26. Cutler GJ, Flood A, Hannan P, Neumark-Sztainer D. Multiple Sociodemographic and Socioenvironmental Characteristics Are Correlated with Major Patterns of Dietary Intake in Adolescents. J Am Diet Assoc. 2011 Feb;111(2):230-40.

Page $12 / 25$ 
27. Petrovic D, de Mestral C, Bochud M, Bartley M, Kivimäki M, Vineis P, et al. The contribution of health behaviors to socioeconomic inequalities in health: A systematic review. Vol. 113, Preventive Medicine. Academic Press Inc.; 2018. p. 15-31.

28. Swaminathan S, Thomas T, Kurpad A V., Vaz M. Perceptions of healthy eating: A qualitative study of school-going children in south India. Health Educ J. 2009;

29. Bailey C, Garg V, Kapoor D, Wasser H, Prabhakaran D, Jaacks LM. Food Choice Drivers in the Context of the Nutrition Transition in Delhi, India. J Nutr Educ Behav. 2018;

30. Seguin R, Connor L, Nelson M, Lacroix A, Eldridge G. Understanding barriers and facilitators to healthy eating and active living in rural communities. J Nutr Metab. 2014 Dec 10;2014.

31. Moitra P, Madan J. Perceived barriers and facilitators of healthy eating and physical activity: focus groups with children, parents and teachers in Mumbai, India. Int J Community Med Public Heal [Internet]. 2020 May 27 [cited 2020 Oct 14];7(6):2363. Available from: http://www.ijcmph.com

32. Zhang Z, Farris KL, Sun MC, Dailey RM, Donovan EE. Parenting Practices, Autonomous Motivation, and Adolescent Diet Habits. J Res Adolesc. 2020 Sep 1;30(3):800-16.

33. Chansukree P, Rungjindarat N. Social Cognitive Determinants of Healthy Eating Behaviors in Late Adolescents: A Gender Perspective. J Nutr Educ Behav. 2017 Mar 1;49(3):204-210.e1.

34. Rathi N, Riddell L, Worsley A. Indian adolescents' perceptions of the home food environment. BMC Public Health [Internet]. 2018 Jan 22 [cited 2020 May 17];18(1):169. Available from:

https://bmcpublichealth.biomedcentral.com/articles/10.1186/s12889-018-5083-8

35. Rathi N, Riddell L, Worsley A. Parents' and teachers' views of food environments and policies in Indian private secondary schools. Int J Environ Res Public Health. 2018 Jul 19;15(7).

36. Correa N, Rajaraman D, Swaminathan S, Vaz M, Jayachitra KG, Lear SA, et al. Perceptions of healthy eating amongst Indian adolescents in India and Canada. Appetite. 2017;

37. Rathi N, Riddell L, Worsley A. What influences urban Indian secondary school students' food consumption? - A qualitative study. Appetite. 2016 Oct 1;105:790-7.

38. Municipal Corporation of Greater. No Title [Internet]. Available from: http://dm.mcgm.gov.in/ward-directory

39. Pawar S V., Choksey AS, Jain SS, Surude RG, Rathi PM. Prevalence of overweight and obesity in 4 schools of south Mumbai. J Clin Diagnostic Res. 2016 Mar 1;10(3):0C01-2.

40. Kumar S, Ray S, Roy D, Ganguly K, Dutta S, Mahapatra T, et al. Exercise and eating habits among urban adolescents: a cross-sectional study in Kolkata, India. BMC Public Health [Internet]. 2017 May 18 [cited 2020 Dec 23];17(1):1-14.

Available from: https://link.springer.com/articles/10.1186/s12889-017-4390-9

41. Rathi N, Riddell L, Worsley A. Food consumption patterns of adolescents aged 14-16 years in Kolkata, India.

42. Rodrigues PRM, Luiz RR, Monteiro LS, Ferreira MG, Gonçalves-Silva RMV, Pereira RA. Adolescents' unhealthy eating habits are associated with meal skipping. Nutrition. 2017 Oct 1;42:114-120.e1.

43. Moitra P, Verma P, Madan J. Development and validation of a questionnaire measuring knowledge, attitudes , and practices ( KAP) to healthy eating and activity patterns in school children ( HEAPS ). Nutr Health. 2021;

44. Moitra P, Madan J, Verma P. Development of the Food Related Environments at School and Home Questionnaire (FRESH-Q) [Internet]. [cited 2021 Jun 10]. Available from:

https://academic.oup.com/cdn/article/5/Supplement_2/879/6293317

45. Green SH, Glanz K. Development of the Perceived Nutrition Environment Measures Survey. Am J Prev Med. 2015 Jul 1;49(1):50-61.

46. Vereecken C, De Henauw S, Maes L, Moreno L, Manios Y, Phillipp K, et al. Reliability and validity of a healthy diet determinants questionnaire for adolescents. Public Health Nutr. 2009;12(10):1830-8.

Page $13 / 25$ 
47. Rosenkranz RR, Dzewaltowski DA. Model of the home food environment pertaining to childhood obesity. Vol. 66, Nutrition Reviews. 2008. p. 123-40.

48. Ghaffar SA, Talib RA, Karim NA, Malaysia K, Raja J, Aziz MA, et al. Food Choices and Diet Quality in the School Food Environment: A Qualitative Insight from the Perspective of Adolescents. Vol. 15, Malaysian Journal of Medicine and Health Sciences. 2019.

49. Glanz K, Bishop DB. The Role of Behavioral Science Theory in Development and Implementation of Public Health Interventions. Annu Rev Public Health. 2010 Mar;31(1):399-418.

50. Pabayo R, Spence JC, Cutumisu N, Casey L, Storey K. Sociodemographic, behavioural and environmental correlates of sweetened beverage consumption among pre-school children. Public Health Nutr [Internet]. 2012 Aug [cited 2021 Nov 11];15(8):1338-46. Available from: https://pubmed.ncbi.nlm.nih.gov/22269184/

51. Zarnowiecki DM, Parletta N, Dollman J. The role of socio-economic position as a moderator of children's healthy food intake. Br J Nutr. 2014 Sep 14;112(5):830-40.

52. Attorp A, Scott JE, Yew AC, Rhodes RE, Barr SI, Naylor PJ. Associations between socioeconomic, parental and home environment factors and fruit and vegetable consumption of children in grades five and six in British Columbia, Canada. BMC Public Health [Internet]. 2014 Feb 11 [cited 2021 Feb 9];14(1):150. Available from:

http://bmcpublichealth.biomedcentral.com/articles/10.1186/1471-2458-14-150

53. Macfarlane A, Crawford D, Ball K, Savige G, Worsley A. Adolescent home food environments and socioeconomic position. Vol. 16, Asia Pac J Clin Nutr. 2007.

54. Cuevas García-Dorado S, Cornselsen L, Smith R, Walls H. Economic globalization, nutrition and health: a review of quantitative evidence. Global Health [Internet]. 2019 Dec 20 [cited 2020 May 17];15(1):15. Available from: https://globalizationandhealth.biomedcentral.com/articles/10.1186/s12992-019-0456-z

55. Karki A, Shrestha A, Subedi N. Prevalence and associated factors of childhood overweight/obesity among primary school children in urban Nepal. BMC Public Health [Internet]. 2019 Aug 6 [cited 2020 Aug 29];19(1):1055. Available from: https://bmcpublichealth.biomedcentral.com/articles/10.1186/s12889-019-7406-9

56. Tyrrell RL, Greenhalgh F, Hodgson S, Wills WJ, Mathers JC, Adamson AJ, et al. Food environments of young people: Linking individual behaviour to environmental context. J Public Heal (United Kingdom). 2017;

57. Pineda E, Swinburn B, Sassi F. Effective school food environment interventions for the prevention of childhood obesity: systematic review and meta-analysis. Lancet. 2019 Nov 1;394:S77.

58. He M, Tucker P, Gilliland J, Irwin JD, Larsen K, Hess P. The influence of local food environments on adolescents' food purchasing behaviors. Int J Environ Res Public Health. 2012 Apr;9(4):1458-71.

59. Bhatt R, Madan J, Moitra P. Determinants of Food Choice in a School Environment. Indian J Public Heal Res Dev [Internet]. 2019 Nov 13 [cited 2021 Apr 2];10(9):302-7. Available from:

http://medicopublication.com/index.php/ijphrd/article/view/4929

60. Zarnowiecki DM, Dollman J, Parletta N. Associations between predictors of children's dietary intake and socioeconomic position: A systematic review of the literature. Obes Rev. 2014;15(5):375-91.

61. Pearson N, Biddle SJH, Gorely T. Family correlates of fruit and vegetable consumption in children and adolescents: A systematic review. Vol. 12, Public Health Nutrition. 2009. p. 267-83.

62. Wolnicka K, Taraszewska AM, Jaczewska-Schuetz J, Jarosz M. Factors within the family environment such as parents' dietary habits and fruit and vegetable availability have the greatest influence on fruit and vegetable consumption by Polish children. Public Health Nutr. 2015 Nov 14;18(15):2705-11.

63. Nawab S, Madan J, Moitra P. Nutritional knowledge of the parents and home food environment of 10 to 12 year old children of Mumbai. 114 Int J Physiol [Internet]. 2019 [cited 2021 Apr 2];4(2):114-9. Available from:

www.journalofsports.com

Page 14/ 25 
64. Diep CS, Chen TA, Davies VF, Baranowski JC, Baranowski T. Influence of Behavioral Theory on Fruit and Vegetable Intervention Effectiveness Among Children: A Meta-Analysis. J Nutr Educ Behav. 2014 Nov 1;46(6):506-46.

\section{Tables}

Table 1

Demographic characteristics of 10-12 years old adolescents in the study 


\begin{tabular}{|c|c|c|c|c|}
\hline Characteristics & Overall & Public Schools & Private Schools & p-value \\
\hline Number of Participants & $712(100.0)$ & $328(46.1)$ & 384 (53.9) & 0.532 \\
\hline \multicolumn{5}{|l|}{ Sex } \\
\hline Boys & $369(51.8)$ & $192(58.5)$ & $177(46.1)$ & \multirow[t]{2}{*}{0.267} \\
\hline Girls & $343(48.2)$ & $136(41.5)$ & 207 (53.9) & \\
\hline \multicolumn{5}{|l|}{ Grade in which studying } \\
\hline $6^{\text {th }}$ Grade & $362(50.8)$ & $174(53.0)$ & $188(49.0)$ & \multirow[t]{3}{*}{0.537} \\
\hline $7^{\text {th }}$ Grade & $350(49.2)$ & $154(47.0)$ & $196(51.0)$ & \\
\hline Age (in years) a & $10.9(1.1)$ & $11.2(1.1)$ & $10.8(0.9)$ & \\
\hline \multicolumn{5}{|l|}{ Religion } \\
\hline Hindu & $427(60.0)$ & $214(65.2)$ & $213(55.5)$ & \multirow{4}{*}{$<0.001^{\star \star}$} \\
\hline Muslim & $234(32.9)$ & $105(32.0)$ & $129(33.6)$ & \\
\hline Christian & $32(4.5)$ & $5(1.5)$ & $27(7.0)$ & \\
\hline Others (Jain, Parsi, Buddhist) & $19(2.7)$ & $4(1.2)$ & $15(3.9)$ & \\
\hline \multicolumn{5}{|l|}{ Type of living arrangement } \\
\hline Nuclear family & $418(58.7)$ & $121(36.9)$ & $297(77.3)$ & \multirow[t]{3}{*}{$0.004^{*}$} \\
\hline Joint family & $189(27.8)$ & $138(42.1)$ & $60(15.3)$ & \\
\hline Extended family & $96(13.5)$ & $69(21.0)$ & $27(7.0)$ & \\
\hline \multicolumn{5}{|l|}{ Education of father } \\
\hline Professional & $164(23.0)$ & $50(15.2)$ & $114(29.7)$ & \multirow{5}{*}{$<0.001^{\star \star}$} \\
\hline Postgraduate or graduate & $344(48.3)$ & $120(36.6)$ & $224(58.3)$ & \\
\hline Post high school/ high school & $116(16.3))$ & $78(23.8)$ & $38(9.9)$ & \\
\hline Middle/ primary school certificate & $70(9.8)$ & $62(18.9)$ & $8(2.1)$ & \\
\hline Illiterate & $18(2.5)$ & $18(5.5)$ & $0(0.0)$ & \\
\hline \multicolumn{5}{|l|}{ Education of mother } \\
\hline Professional & $76(10.2)$ & $2(0.6)$ & $74(19.3)$ & \multirow{5}{*}{$<0.001^{\star \star}$} \\
\hline Postgraduate or graduate & $256(36.0)$ & $67(20.4)$ & $189(49.2)$ & \\
\hline Post high school/ high school & $200(28.1)$ & $117(35.7)$ & $83(21.6)$ & \\
\hline Middle/ primary school certificate & $118(16.6)$ & $92(28.0)$ & $26(6.8)$ & \\
\hline Illiterate & $62(8.7)$ & $50(15.2)$ & $12(3.1)$ & \\
\hline \multicolumn{5}{|l|}{ Monthly family income (INR) } \\
\hline$<30,000$ & $117(20.6)$ & $114(41.0)$ & $3(1.0)$ & \multirow{3}{*}{$<0.001^{\star \star}$} \\
\hline$<50,000$ & $164(28.0)$ & $109(39.2)$ & $55(17.9)$ & \\
\hline $50,000-1,00,000$ & $182(31.2)$ & $54(19.4)$ & $128(41.6)$ & \\
\hline
\end{tabular}


INR; Indian Rupee; ${ }^{*}$ p value $<0.05 ;{ }^{* *} p$ value $<0.001$.

Data are presented as number (percentage) or ${ }^{\mathrm{a}}$ mean (standard deviation).

$\mathrm{p}$ values are obtained from chi-square tests to estimate the difference between adolescents attending public and private schools

\section{Table 2}

Eating habits and school and home food environment characteristics of 10-12 years old adolescents ( $n=712)$ in the study 


\begin{tabular}{|c|c|c|c|c|c|}
\hline Characteristics & Never & Sometimes & Often & Frequently & Always \\
\hline \multicolumn{6}{|l|}{ Eating habits ${ }^{a}$} \\
\hline \multirow{2}{*}{$\begin{array}{l}\text { Have breakfast at home before leaving for } \\
\text { school }\end{array}$} & \multirow{2}{*}{$\begin{array}{l}205 \\
(28.8)\end{array}$} & $188(26.4)$ & $115(16.2)$ & $110(15.4)$ & $94(13.2)$ \\
\hline & & $365(51.3)$ & $119(16.7)$ & $132(18.5)$ & $64(9.0)$ \\
\hline Carry Snacks (Tiffın) to School & $32(4.5)$ & $267(37.5)$ & $139(19.5)$ & $108(15.2)$ & 39 (5.5) \\
\hline Carry fruits to school & $\begin{array}{l}159 \\
(22.3)\end{array}$ & $210(29.5)$ & $176(24.7)$ & $156(21.9)$ & $88(12.4)$ \\
\hline Carry healthy snacks to school & $82(11.5)$ & $111(15.6)$ & $212(29.8)$ & $293(41.2)$ & $41(5.8)$ \\
\hline Carry unhealthy snacks to school & $55(7.7)$ & $71(10.0)$ & $108(15.2)$ & $312(43.8)$ & $191(26.8)$ \\
\hline $\begin{array}{l}\text { Watch television/ screens while eating at } \\
\text { home }\end{array}$ & \multicolumn{2}{|l|}{$30(4.2)$} & & & \\
\hline \multicolumn{6}{|l|}{ School food environment ${ }^{b}$} \\
\hline \multirow{2}{*}{$\begin{array}{l}\text { Frequency of purchasing any food/beverage } \\
\text { at school } \\
\text { Frequency of availability of specific foods at } \\
\text { school }\end{array}$} & $\begin{array}{r}79 \\
(11.1)\end{array}$ & $\begin{array}{r}91 \\
(12.8)\end{array}$ & $\begin{array}{l}312 \\
(43.8)\end{array}$ & $\begin{array}{l}118 \\
(16.6)\end{array}$ & $\begin{array}{l}112 \\
(15.7)\end{array}$ \\
\hline & & $156(21.9)$ & $129(18.1)$ & - & $101(14.2)$ \\
\hline \multirow{3}{*}{$\begin{array}{l}\text { 1. Fruits, fruit juices } \\
\text { 2. Healthy Snacks (poha, upma, sandwich, } \\
\text { roti /rice) } \\
\text { 3. Unhealthy Snacks (samosa/ vada pav/ } \\
\text { pav bhaji) }\end{array}$} & $(45.8)$ & $187(26.3)$ & 134 (18.8) & - & $102(14.3)$ \\
\hline & $\begin{array}{l}289 \\
(40.6)\end{array}$ & $45(6.3)$ & $36(5.1)$ & - & $612(86.0)$ \\
\hline & $19(2.7)$ & & & & \\
\hline $\begin{array}{l}\text { Frequency of purchasing specific foods at } \\
\text { school }\end{array}$ & & $212(29.8)$ & $141(19.8)$ & - & $28(3.9)$ \\
\hline \multirow{4}{*}{$\begin{array}{l}\text { 1. Fruits, fruit juices } \\
\text { 2. Healthy Snacks (poha/upma/ sandwich/ } \\
\text { roti/rice) } \\
\text { 3. Unhealthy Snacks (samosa/ vada pav/ } \\
\text { pav bhaji/) }\end{array}$} & $\begin{array}{l}331 \\
(46.5)\end{array}$ & $211(29.6)$ & $171(24.0)$ & - & $44(6.2)$ \\
\hline & 286 & $188(26.4)$ & $172(24.2)$ & - & $148(20.8)$ \\
\hline & $(40.2)$ & & & & \\
\hline & $\begin{array}{l}204 \\
(28.7)\end{array}$ & & & & \\
\hline \multicolumn{6}{|l|}{ Home Food Environment ${ }^{a}$} \\
\hline \multicolumn{6}{|l|}{ Availability of foods at home } \\
\hline \multirow{3}{*}{$\begin{array}{l}\text { 1. Fruits } \\
\text { 2. Vegetables } \\
\text { 3. Healthy snacks }\end{array}$} & $\begin{array}{l}110 \\
(154)\end{array}$ & $94(13.2)$ & $101(14.2)$ & $254(35.7)$ & $153(21.5)$ \\
\hline & $5(07)$ & $22(3.1)$ & $55(7.7)$ & $334(46.9)$ & $296(41.6)$ \\
\hline & & $155(21.8)$ & $132(18.5)$ & $176(24.7)$ & $81(11.4)$ \\
\hline $\begin{array}{l}\text { d. Unhealthy snacks } \\
\text { 1. Carbonated beverages }\end{array}$ & $\begin{array}{l}108 \\
(23.6)\end{array}$ & $58(8.1)$ & $102(14.3)$ & $221(31.0)$ & $312(43.8)$ \\
\hline Accessibility and Visibility of foods at home & $19(2.7)$ & $191(26.8)$ & $145(20.4)$ & $110(15.4)$ & $64(9.0)$ \\
\hline \multirow{4}{*}{$\begin{array}{l}\text { 1. Fruits } \\
\text { 2. Healthy snacks } \\
\text { 3. Unhealthy snacks } \\
\text { 4. Carbonated beverages }\end{array}$} & $\begin{array}{l}202 \\
(28.4)\end{array}$ & & & & \\
\hline & & $185(26.0)$ & $113(15.9)$ & $109(15.3)$ & $83(11.7)$ \\
\hline & & $153(21.5)$ & $138(19.4)$ & $172(24.2)$ & $83(11.7)$ \\
\hline & $(31.2)$ & $67(9.4)$ & $96(13.5)$ & $228(32.0)$ & $298(41.9)$ \\
\hline Family Dietary Habits & $\begin{array}{l}166 \\
(23.3)\end{array}$ & & & & \\
\hline
\end{tabular}


2. Have at least a meal at the dining table.

3. Eats out at restaurants/ orders takeaways.

$23(3.2)$

$$
\begin{array}{llll}
89(12.5) & 115(16.2) & 91(12.8) & 318(44.7) \\
167(23.5) & 93(13.1) & 129(18.1) & 170(23.9) \\
343(48.2) & 92(12.9) & 52(7.3) & 12(1.7)
\end{array}
$$

$99(13.9)$

153

(29.9)

a Response Options- Never (0 days), Sometimes (1-2 days), Often (3-4 days), Frequently (5-6 days), Always (6-7 days). ${ }^{\mathrm{b}}$ Response- Never (0 days), Sometimes (1-2 days), Often (3-4 days), Almost always (5-6 days)

\section{Table 3}

Weekly consumption (mean number of days/ week) of unhealthy snacks in 10-12 years old adolescents in Mumbai, India 


\begin{tabular}{|c|c|c|c|c|c|c|}
\hline \multirow{3}{*}{ Unhealthy snack items } & \multicolumn{6}{|c|}{ Weekly Consumption (days/ week) † } \\
\hline & \multicolumn{2}{|c|}{$\begin{array}{l}\text { Overall } \\
(n=712)\end{array}$} & \multicolumn{2}{|c|}{$\begin{array}{l}\text { Public school } \\
(n=328)\end{array}$} & \multicolumn{2}{|c|}{$\begin{array}{l}\text { Private school } \\
(n=384)\end{array}$} \\
\hline & Mean & $\begin{array}{l}95 \% \\
\mathrm{Cl}\end{array}$ & Mean & $\begin{array}{l}95 \% \\
\mathrm{Cl}\end{array}$ & Mean & $\begin{array}{l}95 \% \\
\mathrm{Cl}\end{array}$ \\
\hline \multicolumn{7}{|l|}{ High in fat/fast foods } \\
\hline Pav bhaji & 1.3 & $\begin{array}{l}1.1- \\
1.6\end{array}$ & 0.8 & $0.5-$ & $1.6^{\star \star}$ & $\begin{array}{l}1.4- \\
1.8\end{array}$ \\
\hline Burger/Pizza & 0.6 & & 0.2 & & $11^{\text {** }}$ & \\
\hline Samosa/vada pav & 2.8 & 0.8 & 3.2 & 0.3 & & 1.3 \\
\hline \multirow[t]{2}{*}{ Instant noodles } & 2.1 & $\begin{array}{l}2.4- \\
3.2\end{array}$ & 1.9 & $\begin{array}{l}3.0- \\
3.4\end{array}$ & 2.9 & $\begin{array}{l}2.7- \\
3.0\end{array}$ \\
\hline & & $\begin{array}{l}1.9- \\
2.3\end{array}$ & & $\begin{array}{l}1.7- \\
2.1\end{array}$ & 2.2 & $\begin{array}{l}1.9- \\
2.4\end{array}$ \\
\hline \multicolumn{7}{|l|}{ Snacks with added sugar } \\
\hline Biscuits/cookies & 5.2 & $\begin{array}{l}5.0- \\
5.4\end{array}$ & 6.9 & $\begin{array}{l}6.6- \\
72\end{array}$ & $4.5^{* *}$ & $4.2-$ \\
\hline Cakes/Pastries & 1.0 & & 0.7 & & $14^{* *}$ & \\
\hline \multirow[t]{2}{*}{ Chocolates } & 3.9 & 1.1 & 3.8 & -0.9 & & 1.6 \\
\hline & & $\begin{array}{l}3.6- \\
4.2\end{array}$ & & $\begin{array}{l}3.4- \\
4.3\end{array}$ & 3.9 & $\begin{array}{l}3.5- \\
4.3\end{array}$ \\
\hline \multicolumn{7}{|l|}{ Snacks with added salt } \\
\hline Wafers/Potato chips & 3.4 & $3.1-$ & 2.9 & $2.7-$ & $3.7^{*}$ & $3.5-$ \\
\hline Fried rice/ noodles & 1.2 & & 0.8 & & $16^{* *}$ & \\
\hline Frankie (potato-filled refined flour wraps) & 1.9 & 1.5 & 1.6 & 1.1 & & 2.0 \\
\hline \multirow[t]{2}{*}{$\begin{array}{l}\text { Chinese bhel (puffed rice tossed with chili sauce, soy sauce, } \\
\text { chopped onion, and tomato) }\end{array}$} & 1.2 & $\begin{array}{l}1.7- \\
2.1\end{array}$ & 1.5 & $\begin{array}{l}1.4- \\
1.8\end{array}$ & & $\begin{array}{l}2.0- \\
2.4\end{array}$ \\
\hline & & $\begin{array}{l}1.0- \\
1.4\end{array}$ & & $\begin{array}{l}1.2- \\
1.8\end{array}$ & & $\begin{array}{l}0.6- \\
1.0\end{array}$ \\
\hline Carbonated beverages & 0.9 & $\begin{array}{l}0.6- \\
1.2\end{array}$ & 0.3 & $\begin{array}{l}0.1 \\
-0.5\end{array}$ & $1.7^{\star *}$ & $\begin{array}{l}1.5- \\
1.9\end{array}$ \\
\hline
\end{tabular}

${ }^{*}$ p-value $\leq 0.05,{ }^{* *}$-value $<0.001$

† Weekly consumption values are presented as mean and 95\% Confidence Interval (Cl)

Table 4

Perceptions related to food environments in 10-12 years old adolescents in Mumbai (n (\%) reporting strongly agree/agree ${ }^{\#)}$ 


\begin{tabular}{|c|c|c|c|c|c|}
\hline Perceptions & $\begin{array}{l}\text { Overall } \\
(n= \\
712)\end{array}$ & $\begin{array}{c}\begin{array}{c}\text { Public } \\
\text { School }\end{array} \\
(n= \\
328)\end{array}$ & $\begin{array}{l}\text { Private } \\
\text { School } \\
\qquad(n=384)\end{array}$ & $x^{2}$ & p value \\
\hline \multicolumn{6}{|l|}{ Perceived Susceptibility \& Severity } \\
\hline $\begin{array}{l}\text { Unhealthy eating habits can increase the risk of health } \\
\text { problems }\end{array}$ & $\begin{array}{l}432 \\
(60.7)\end{array}$ & $172(52.4)$ & $260(67.7)$ & 17.324 & $<0.001^{* *}$ \\
\hline $\begin{array}{l}\text { I can become sick if I don't eat enough fruits and } \\
\text { vegetables }\end{array}$ & $\begin{array}{l}318 \\
(44.7)\end{array}$ & $\begin{array}{l}134(40.9) \\
118(36.0)\end{array}$ & $\begin{array}{l}184(47.9) \\
190(49.5)\end{array}$ & $\begin{array}{l}3.521 \\
13.115\end{array}$ & $\begin{array}{l}0.063 \\
0.003^{*}\end{array}$ \\
\hline $\begin{array}{l}\text { Children cannot get diabetes or have high blood } \\
\text { pressure }\end{array}$ & $\begin{array}{l}308 \\
(43.3)\end{array}$ & & & & \\
\hline \multicolumn{6}{|l|}{ Perceived Benefits } \\
\hline $\begin{array}{l}\text { Fruits can fight infections } \\
\text { Vegetables are good for the eyes, bones, and brain } \\
\text { Eating breakfast every day will help me to study better in } \\
\text { school } \\
\text { Eating less unhealthy snacks will keep me fit and strong }\end{array}$ & $\begin{array}{l}567 \\
(79.6) \\
512 \\
(71.9) \\
458 \\
(64.3) \\
587 \\
(82.4)\end{array}$ & $\begin{array}{l}272(82.9) \\
276(84.1) \\
209(63.7) \\
288(87.8)\end{array}$ & $\begin{array}{l}295(76.8) \\
236(61.5) \\
249(64.8) \\
299(77.9)\end{array}$ & $\begin{array}{l}4.049 \\
44.669 \\
0.093 \\
11.971\end{array}$ & $\begin{array}{l}0.054 \\
<0.001^{* *} \\
0.760 \\
<0.001^{* *}\end{array}$ \\
\hline Perceived Barriers & & & & & \\
\hline $\begin{array}{l}\text { Snacks brought from home become cold and } \\
\text { unpleasant } \\
\text { Fruits are not available at the school canteen } \\
\text { Healthy food items (eg fruits/milkshakes) sold in school } \\
\text { are expensive } \\
\text { The homecooked foods are always the same and boring } \\
\text { Salads are rarely served with meals at home }\end{array}$ & $\begin{array}{l}625 \\
(87.8) \\
478 \\
(67.1) \\
359 \\
(50.4) \\
542 \\
(76.1) \\
390 \\
(54.8)\end{array}$ & $\begin{array}{l}285(86.9) \\
238(72.6) \\
189(57.6) \\
243(74.1) \\
219(66.8)\end{array}$ & $\begin{array}{l}340(88.5) \\
240(62.5) \\
170(44.3) \\
299(77.9) \\
171(44.5)\end{array}$ & $\begin{array}{l}0.421 \\
8.169 \\
12.500 \\
1.414 \\
35.462\end{array}$ & $\begin{array}{l}0.516 \\
0.004^{*} \\
0.003^{*} \\
0.236 \\
<0.001^{* *}\end{array}$ \\
\hline Readiness to Change & & & & & \\
\hline $\begin{array}{l}\text { I try to eat fruits in between my meals every day } \\
\text { I want to improve my snacking habits }\end{array}$ & $\begin{array}{l}418 \\
(58.7) \\
289 \\
(40.6)\end{array}$ & $\begin{array}{l}162(49.4) \\
119(36.3)\end{array}$ & $\begin{array}{l}256(66.7) \\
170(44.3)\end{array}$ & $\begin{array}{l}2.624 \\
4.687\end{array}$ & $\begin{array}{l}0.005^{*} \\
0.031^{*}\end{array}$ \\
\hline Self -efficacy & & & & & \\
\hline $\begin{array}{l}\text { I have enough knowledge to make healthy food choices } \\
\text { I can prepare a snack or have fruit as a snack at home }\end{array}$ & $\begin{array}{l}456 \\
(64.0) \\
301 \\
(42.3)\end{array}$ & $\begin{array}{l}196(59.8) \\
132(40.2)\end{array}$ & $\begin{array}{l}260(67.7) \\
169(44.0)\end{array}$ & $\begin{array}{l}4.789 \\
1.045\end{array}$ & 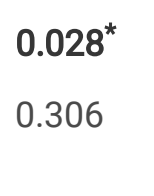 \\
\hline
\end{tabular}

\#Values are expressed as number with percentages in parentheses; ${ }^{*} p$-value $\leq 0.05,{ }^{* *} p$-value $<0.001$

\# Perceptions are based on the Health Belief Model measured on a 3-point scale- Strongly disagree/disagree, neutral, agree/strongly agree 
Comparison of data was done using Pearson's $\chi^{2}$ test of independence, $\mathrm{df}=1$

Table 5

Regression analyses to determine factors associated with unhealthy snack consumption ${ }^{\mathrm{a}}$ in adolescents in Mumbai 


\section{Variables}

Public School Adolescents

$(n=328)$
Private School Adolescents $(n=384)$

OR
p-value

$95 \% \mathrm{Cl}$

\section{Socio-demographic characteristics}

Sex-Boys (Ref: Girls)

Education of father ( Ref: < High school certificate)

Education of mother (Ref: < High school certificate)

Monthly family income (Ref: < 30000 INR)

\begin{tabular}{|c|c|c|c|c|}
\hline 1.75 & $0.69-$ & \multirow{2}{*}{\multicolumn{2}{|c|}{$\begin{array}{l}1.13 \\
0.381\end{array}$}} & $0.93-1.22$ \\
\hline 0.79 & $0.032^{*}$ & & & \\
\hline $1.12^{1.05}$ & $0.132^{0.98-}$ & 2.02 & 1.83 & $\begin{array}{l}1.78- \\
21\end{array}$ \\
\hline $1.27^{1.09}$ & $0.191^{0.91-}$ & & $\begin{array}{l}0.78 \\
\quad<0.001^{* *}\end{array}$ & $0.66-0.82$ \\
\hline $1.10^{1.03}$ & 0.619 & & $\begin{array}{l}2.15 \\
<0.001^{* *}\end{array}$ & $1.98-2.32$ \\
\hline
\end{tabular}

\section{Eating Habits}

Breakfast before going to school (Ref: $<3 \mathrm{~d} /$ week)

Carry Snacks (Tiffin) to School (Ref: $<3 \mathrm{~d} /$ week)

$\begin{array}{llll}1.06^{0.99} & 0.672^{0.95-} & \mathbf{0 . 7 7} & \mathbf{0 . 7 1 - 0 . 8 3} \\ & <0.001^{\text {** }} & \end{array}$

$\begin{array}{cccc}\mathbf{0 . 8 3} & \mathbf{0 . 8 1}^{\mathbf{0 . 8 1}} & \mathrm{C}^{1.06} & 0.563^{0.98-}\end{array}$

\section{School Food Environment}

Availability of fruits (Ref: $<3 \mathrm{~d} /$ week)

Availability of healthy snacks (Ref: $<3 \mathrm{~d} /$ week)

Availability of unhealthy snacks (Ref: $<3 \mathrm{~d} /$ week)

Reasons for purchasing snacks - Taste (Ref: No)

Reasons for purchasing snacks - Price (Ref: No)
1.12
1.01
0.421
$0.88-$
$1.10^{1.01}$
$0.066^{0.98-}$

$1.06^{1.02} 0.203^{0.99-}$

$3.79^{2.60}<0.001^{* *}$

$\begin{array}{cc}{ }_{1.04}^{0.99} & 0.95- \\ 1.10^{1.06} & 0.198 \\ & 0.319\end{array}$

$1.26^{0.99} 0.083^{0.82-}$

$1.08^{0.99} 0.328$

$3.03^{2.87}<0.001^{\text {** }}$

\section{Home Food Environment}

Availability of fruits at home (Ref: $<3 \mathrm{~d} /$ week)

Availability of unhealthy snacks at home (Ref: $<3 \mathrm{~d}$ / week)

Visibility of fruits in easy to reach places (Ref: $<3 \mathrm{~d}$ / week)

\begin{tabular}{|c|c|c|c|}
\hline 0.99 & $0.98-$ & 0.57 & $0.49-$ \\
\hline 1.07 & 0.921 & 0.69 & $<0.001^{\star *}$ \\
\hline $1.41^{1.23}$ & $0.332^{0.98-}$ & $3.46^{2.98}$ & $<0.001^{1 *}$ \\
\hline
\end{tabular}

Visibility of unhealthy snacks in easy to reach places (Ref: $<3$ d/ week)

At least a meal at the dining table (Ref: $<3 \mathrm{~d} /$ week)

Evening meals together (Ref: $<3 \mathrm{~d} /$ week)

Eating out in restaurants (Ref: $<3 \mathrm{~d} /$ week) 
(Ref: strongly disagree, neutral, and disagree)

Pressure to eat veggies during meals

Parents choose time to have snacks
1.02
1.13
$0.782^{0.94-}$
0.71
0.81
$0.031^{*}$
0.99
$0.112^{0.95-}$
0.94
0.237
$0.83-$

Allowed to eat fast foods only on weekends

\begin{tabular}{|c|c|c|c|c|}
\hline $1.06^{1.03}$ & $0.313^{0.99-}$ & $1.20^{1.12}$ & 0.444 & $1.04-$ \\
\hline $1.28^{1.14}$ & $\begin{array}{l}0.98- \\
0.271^{-}\end{array}$ & $1.15^{1.01}$ & 0.521 & $0.97-$ \\
\hline 1.01 & $0.289 \quad 0.93-1.04$ & $0.72^{0.67}$ & $<0.001$ & $0.62-$ \\
\hline
\end{tabular}

Adolescents' Perceptions (Ref: strongly disagree, neither agree nor disagree and disagree)

Perceived susceptibility (Unhealthy eating habits can increase risk of health problems)
1.01
$0.662^{0.92-1.12}$
1.01
0.911
$0.94-1.18$

Perceived benefits (Fruits can fight infections)

Perceived benefits (Vegetables are good for...)

Perceived barriers (Fruits are not available at school)
$\begin{array}{cccc}0.99 & 0.98-1.08 & 1.16 & 0.97-1.22 \\ 0.344 & & 0.652 & \end{array}$
$\begin{array}{llll}0.91 & 0.88-1.12 & 0.99 & 0.89-1.19\end{array}$
0.218
0.0871

Perceived barriers (Homecooked foods are the same....)

Perceived barriers (Healthy foods are expensive)

Readiness to change (I try to eat fruits every day)
$1.98 \underset{1.67-2.31}{1} \quad 2.03 \quad 1.96-2.12$
$<0.001^{\text {** }}$

Self-efficacy (I can prepare a snack or have fruit....)

\begin{tabular}{|c|c|c|c|}
\hline${ }^{1.11} 0.066$ & $0.97-1.22$ & $\begin{array}{l}3.11 \\
<0.001^{\text {* }}\end{array}$ & $2.34-4.65$ \\
\hline $\begin{array}{l}4.97<0.001^{*} \\
\end{array}$ & $2.98-5.19$ & $\begin{array}{l}1.78 \\
<0.001^{* *}\end{array}$ & $1.32-2.22$ \\
\hline $\begin{array}{l}0.79 \\
0.009^{*}\end{array}$ & $0.62-0.92$ & $\begin{array}{l}1.11 \\
0.512\end{array}$ & $0.99-1.24$ \\
\hline 990.123 & $0.93-1.08$ & $\begin{array}{l}0.88 \\
0.043^{*}\end{array}$ & $0.76-0.99$ \\
\hline
\end{tabular}

OR, odds ratio. $\mathrm{Cl}$, confidence interval. * $\mathrm{p} \leq 0.05,{ }^{\star \star} \mathrm{p}<0.001$.

a Dependent variable- Highest tertile of unhealthy snack consumption compared with the low and moderate tertiles of consumption of unhealthy snacks and carbonated beverages/d in adolescents.

OR values that show significant associations with higher consumption of unhealthy snacks are highlighted.

\section{Supplementary Files}

This is a list of supplementary files associated with this preprint. Click to download. 
- SupplementaryTable2.docx

- SupplementaryTable1.docx 